\title{
Ear Pinna: A Privileged DNA Electroporation Site for Inducing Strong Th1 Immune Responses
}

\author{
Jing $\mathrm{Ni}^{1}$, Britta Nolte ${ }^{1}$, Gaëlle Vandermeulen ${ }^{2}$, Veronique Preat ${ }^{2}$, Daniel Scherman ${ }^{3}$, Volker \\ Schirrmacher ${ }^{1}$ and Philippe Fournier ${ }^{1 *}$ \\ ${ }^{1}$ Division of Cellular Immunology, German Cancer Research Center, Heidelberg, Germany \\ ${ }^{2}$ Université catholique de Louvain, Department of Pharmaceutics, UCL73.20, 1200 Brussels, Belgium \\ ${ }^{3}$ Inserm, U640, Paris, F-75006 France; CNRS, UMR8151, Paris, F-75006 France; Université Paris Descartes, Faculté \\ de Pharmacie, Chemical and Genetic Pharmacology Laboratory, Paris, F-75270 France; Ecole Nationale Supérieure \\ de Chimie de Paris, Paris, F-75005 France
}

\begin{abstract}
DNA vaccination appears a very attractive approach for inducing immune responses towards the encoded antigen, but studies in large animals and in humans revealed weaknesses of such responses. In this study, we evaluated a new approach based on a new device combining DNA vaccination with electroporation (EP) at the ear pinna site. Under optimal EP conditions, the expression of the DNA encoded antigen and the induced immune responses were considerably increased. Very interestingly, DNA vaccination using EP at the ear pinna induced much stronger cellular immune responses than at the flank skin although antigen expression was similar at both sites. As compared to vaccination at the ear pinna without EP, IFN- $\gamma$ but not IL-4 production by splenocytes from immunized mice was significantly enhanced. In contrast, IL-4 but not IFN- $\gamma$ production was increased by EP at the flank skin. The vaccination site of the ear pinna combined with EP route even provided therapeutic effects in a mouse tumor model.
\end{abstract}

In conclusion, this study highlights the ear pinna as a privileged site for the induction of strong Th1 polarized cellular immunity against a defined antigen when combining DNA vaccination with EP.

Keywords: Antigen expression, immunization, electroporation, vaccination, tumor therapy.

\section{INTRODUCTION}

Genetic immunization using naked DNA [1, 2] offers considerable advantages over conventional vaccines:

(i) high stability of plasmid DNA and relative temperature insensitivity making them highly suitable for mass production and easy transportation in both industrialized and developing countries,

(ii) low manufacturing costs,

(iii) lack of infection risks that are associated with attenuated viral vaccines,

(iv) capacity to target multiple antigens (Ags) on one plasmid by inserting several open reading frames from one or more genes and

(v) absence of intrinsic immunogenicity allowing successful boost after DNA vaccination without producing a heterologous immune response.

It has been shown to be effective and safe for inducing protective immunity in preclinical models of infectious diseases [3-6], cancer [7-10] and autoimmune diseases [11-13].

After over a decade of active research, DNA vaccines are now reaching the commercial market with recent approvals of West Nil virus in horses [14], infectious hematopoetic

*Address Correspondence to this author at the German Cancer Research Center (DKFZ), Im Neuenheimer Feld 280, 69120 Heidelberg, Germany; Fax: +496221 424962; E-mail: p.fournier@dkfz.de necrosis virus in salmon [15] and melanoma in dogs [16-18]. However, despite more than 200 clinical trials to date [19], no plasmid DNA products have received approval by FDA for use in humans. There have been, however, numerous preclinical and clinical studies for most types of cancer [20].

One important problem for all DNA vaccines relates to the translation of therapy data from small animals to large animals [21] and to humans [22-26]. The efficacy in humans has been disappointing [24, 26, 27], partly due to the difficulties in scaling up DNA vaccine dose and injection volume for human application [28]. Low vaccine dose results in poor Ag expression and reduced immunogenicity [29].

In contrast to conventional vaccines, DNA vaccine must be delivered intracellularly in order to elicit production of the antigen with minimal toxic effects. Cellular uptake of DNA appears then to be a significant limiting factor for transfection efficiency in vivo. To overcome this problem, different delivery approaches have been used to enhance the level of transfection and consequently of antigen expression from plasmids [30]. Instead of injection of naked DNA plasmids [31], they can be combined with liposomes [30] or applied by gene guns [32], by microseeding or puncture [33], by micromechanical disruption methods [34, 35]. Viral vector systems can also be used [36, 37]. All these methods were capable to improve the induction of $\mathrm{Ag}$ specific immunity [38-42].

In this study, we employed electroporation (EP) because during the past few years great potential of this new technol- 
ogy was demonstrated $[43,44]$. It has been evaluated in studies involving delivery of plasmid DNA in vivo to different types of tissues. The transfection efficiency was 10-1000 folds greater than that of naked DNA injection with remarkable reduction of an inter-animal variability [45]. EP is based on the creation of pores in cell membranes through the application of electrical pulses for allowing the cellular entry of macromolecules such as DNA [46]. The exact mechanism remains elusive. Both active [47-49] and passive mechanism involving simple diffusion of DNA through the membrane [50] have been proposed. The vaccination efficiency of EP is also due to an induced inflammation process which leads to the recruitment of DCs, macrophages and lymphocytes to the injection site [51, 52]. Recent technological developments in the fields of EP involve devices that are capable of delivering series of pulses controlling the pulse length, the electric field strength and various other parameters.

Intramuscular (i.m.) [53] and intranasal injections are commonly used routes of administration for DNA vaccines [54-57]. But DNA immunization has also been effective in eliciting an immune response $[1,2]$ with various other administration routes such as intraperitoneal, intravenous, oral, ocular, and transdermal/topical administration [58].

Methods based on electric pulse for increasing DNA delivery into cells have mostly been applied to skin. This is an attractive site for DNA vaccination since this is the most accessible somatic tissue for gene transfer and it can be monitored conveniently. More importantly, for vaccination purposes, it is an active immune surveillance tissue which is especially rich in specialized cells enhancing immune responses [59] such as dendritic cells (DCs): epidermal Langerhan's cells (LCs) and dermal DCs [60]. By targeting the skin, DNA immunization attempts to produce an immunologically efficacious response $[1,61]$. Upon skin application, DNA vaccines allow for protein expression in a variety of cells, including keratinocytes, LCs, and dermal DCs, which are located in the two main areas of the skin, the epidermis and the dermis [61]. After maturation, DCs can migrate to local lymph nodes where presentation of antigens to $\mathrm{T}$ cells can occur and initiate a variety of immunological responses $[62,63]$. In mouse models, intradermal (i.d.) injection is usually applied for vaccination purposes to abdominal or flank skin. Interestingly, in our previous studies with the highly metastatic lymphoma ESb tumor, it was shown that the ear pinna is a privileged site (compared to subcutaneous (s.c.) tumor inoculation) for the induction of antitumor immunity, preventing the outgrowth of an otherwise lethal dose of tumor cells [64]. Further studies corroborated the superiority of the ear pinna in comparison to i.m. and i.d. immunization sites also for DNA and RNA based vaccines $[65,66]$.

In this study, we compared the efficiency of EP combined with DNA vaccination at different immunization sites in term of antigen expression and of immune responses against the plasmid antigen. After having optimized the conditions of DNA EP, we demonstrate that intradermal DNA injection in combination with EP at the ear pinna but not at the flank skin of mice induces Th1 polarized immune responses which exert strong anti-tumor effects.

\section{MATERIALS AND METHODS}

Cells. All cell lines were obtained from the tumor cell bank of the German Cancer Research Center (DKFZ, Heidelberg, Germany). Cell culture media were supplemented with $2 \mathrm{mM}$ L-glutamine, $10 \mathrm{mM}$ HEPES, $100 \mathrm{U} / \mathrm{ml}$ penicillin and $100 \mu \mathrm{g} / \mathrm{ml}$ streptomycin (all purchased from Gibco Invitrogen, Karlsruhe, Germany). P815, a mastocytoma, and its lacZ-transfected variant P13.1 were cultivated in RPMI1640 medium with supplements (as indicated above) as well as $\beta$-mercaptoethanol at a final concentration of $50 \mu \mathrm{M}$. The medium for lacZ transfected cells was supplemented with $200 \mu \mathrm{g} / \mathrm{mL}$ G418 to maintain stable lacZ gene expression. DA3, a mammary carcinoma cell line, and DA3-EpCAM (DA3 transfected with human EpCAM gene) were cultivated in RPMI-1640 medium complemented with supplements (as indicated above) and with $\beta$-mecarptoethanol $(50 \mu \mathrm{M})$.

Mouse tumor models. Female DBA/2 mice were purchased from Charles River WIGA (Sulzfeld, Germany) and used at 6-8 weeks of age. These mice were used for the optimization of the voltage conditions, the analysis of antigen expression and the ex vivo analysis of the cytotoxic response against the target tumor cells.

Therapy experiments were performed with female Balb/c mice which were also obtained from Charles River WIGA. During tumor challenge, mice were injected s.c. with $1 \times 10^{7}$ DA3-EpCAM or DA3 tumor cells into the flank. For therapeutic immunization DNA plasmids were injected 1, 2, 3 and 4 weeks after tumor inoculation. All mice were monitored twice a week for tumor development and were killed when the mean tumor diameter reached $20 \mathrm{~mm}$, in accordance with the guidelines of the animal house facility of our institute.

DNA plasmids. The plasmid coding for the luciferase under the control of a CMV promoter (CMV-luciferase) was kindly provided by Dr. Daniel Scherman (INSERM, Institut National de la Santé et de la Recherche Médicale, Paris, France). The plasmid pCMV SPORT- $\beta$ gal was purchased from Invitrogen (Karlsruhe, Germany). A plasmid encoding $1.5-\mathrm{kb}$ of the human EpCAM gene (extracellular and transmembrane domain) was kindly provided by Dr. Frank Momburg (DKFZ, German Cancer Research Center, Heidelberg, Germany). To prepare the plasmid (leading to EpCAM expression under control of a CMV promoter), the EpCAM DNA fragment was cloned into pTandem-1 (Novagen, Darmstadt, Germany) to prepare CMV-EpCAM. All plasmids were grown in Escherichia coli (Top 10) and purified using the Qiagen Endo-free Gega Prep Kit (Qiagen, Hilden, Germany). The DNA stocks having a 260:280 ratio from 1.8 to 2.0, were prepared in Endo-free water (B. Braun Melsungen $\mathrm{AG}$, Melsungen, Germany) and stored at $-20^{\circ} \mathrm{C}$. For in vivo injections, the DNA was diluted and adjusted to 0.5 $\mathrm{mg} / \mathrm{mL}$ or $1 \mathrm{mg} / \mathrm{mL}$ in Endo-free PBS (PromoCell, Heidelberg, Germany) just before use.

DNA immunizations. Mice were anesthetized by intraperitoneal (i.p.) injection of Rompun $(4.5 \mathrm{mg} / \mathrm{kg} \mathrm{BW}$ ) (Bayer, Leverkusen, Germany) and Ketanest (45 mg/kg BW) (Bayer, Leverkusen, Germany). DNA with the amount of $25 \mu \mathrm{g} / 50$ $\mu \mathrm{L}$ (for gene expression and immune responses) or $50 \mu \mathrm{g} / 50$ $\mu \mathrm{L}$ (for the therapeutic tumor model), dissolved in PBS, was injected into ear pinna (i.e.) or shaved flank skin by using a 


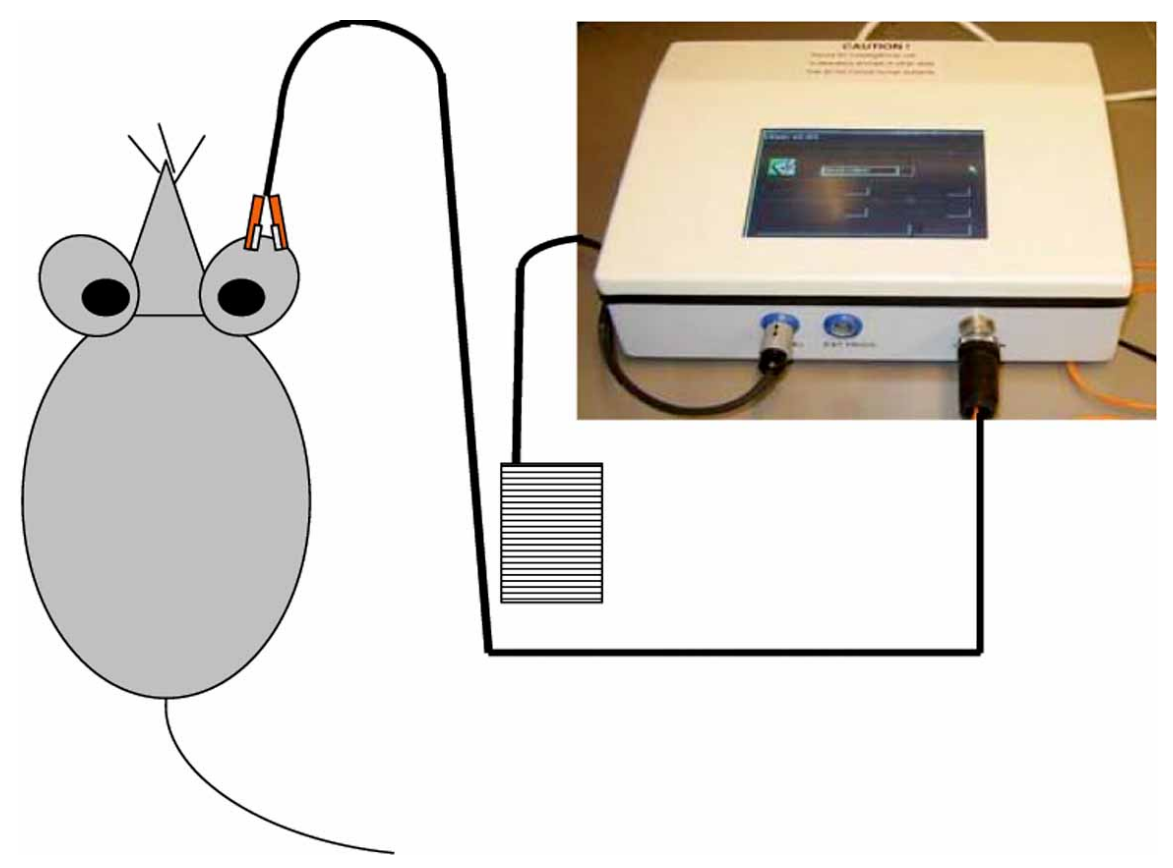

Fig. (1). EP device.

The device ELGEN1000 EP-based DNA delivery system (Inovio) was used through all this study. It is composed of two parts: the pulses generator and the caliper electrodes. A pedal allows an easy control of the pulse generator by a foot. After DNA injection with $50 \mu \mathrm{L}$ volume, Ultrasound gel was applied to the local injection site. Caliper electrode was placed at the injection site, with $1 \mathrm{~mm}$ distance between the two electrodes. EP was performed by pressing the pedal followed by a triple beeps which indicated successful EP. Electrodes are connected to a pulse stimulator which generates the electric signals necessary to enhance the intradermal delivery of the vaccine using the optimal parameters suggested by the Inovio company and indicated in the Table $\mathbf{1}$.

BD Insulin syringe (29-gauge, BD Biosciences, Heidelberg, Germany).

Immediately after DNA application, EP was performed using the ELGEN1000 DNA delivery system (Inovio, San Diego, USA) connected to caliper electrodes (as shown in Fig. 1). Various voltages (from 40 to $120 \mathrm{~V} / \mathrm{cm}$ ) and other optimal parameters as timing and sequence of pulses (see Table 1) which are important for effective DNA delivery were applied as suggested by the provider of the device.

Table 1. Electroporation Parameters

\begin{tabular}{|c|c|}
\hline Time : & $20 \mathrm{~ms}$ \\
\hline Volt : & optimized in this study \\
\hline Number of sequences : & 1 \\
\hline Number of trains : & $100 \mathrm{~ms}$ \\
\hline Pulse Delay : & $100 \mathrm{~ms}$ \\
\hline Train Delay : & $1000 \mathrm{~mA}$ \\
\hline Current Limit : & \\
\hline
\end{tabular}

In vivo imaging of mice. The IVIS100 imaging system (Xenogen, Alameda, USA) was used for imaging mice. Dluciferin potassium salt (SYNCHEM, Huddersfield, UK), the firefly luciferase substrate, was diluted to a final concentration of $30 \mathrm{mg} / \mathrm{mL}$ in PBS. Imaging of mice was made $5 \mathrm{~min}$ after the i.p. injection of $100 \mu \mathrm{L}$ D-luciferin solution. Biolu- minescent color images were acquired by Living Image 2.50 software overlay (Xenogen, Alameda, USA) and analyzed by Igor Pro 4.09A software. Bioluminescence signals are expressed in units of photons per second per cubic centimeter per steradian ( $\left.\mathrm{p} / \mathrm{sec} / \mathrm{cm}^{2} / \mathrm{sr}\right)$.

ELISA. Blood samples were collected from the retroorbital plexus of mice 2 weeks after DNA immunization. Plasma were prepared and stored at $-20^{\circ} \mathrm{C}$. Titers of anti- $\beta$ gal antibodies were assessed by ELISA. Briefly, 96-well plates were coated overnight with purified $\beta$-gal protein (Sigma, Taufkirchen, Germany) with PBS, the plates were then blocked with $2 \%$ milk in PBS for 30 min at $37^{\circ} \mathrm{C}$. Plasma samples were serially diluted in this buffer and applied to the plates for $2 \mathrm{~h}$ at room temperature. After further washing steps with $0.05 \%$ Tween-20/PBS, bound antibodies were detected with a peroxidase-conjugated goat anti-mouse $\mathrm{IgG}+\mathrm{M}$ immunoglobulin (1:5000, Dianova, Hamburg, Germany). The plates were then washed and finally developed with TMB substrate (KPL, Gaithersburg, USA) and optical density was then read at $450 \mathrm{~nm}$. A monoclonal mouse anti$\beta$-gal antibody (Ab) (Sigma, Munich, Germany) was used as a positive control. Titers were calculated by the formula from the $\mathrm{Ab}$ curves when the $\mathrm{OD}$ at $450 \mathrm{~nm}$ was equal to 0.5 OD unit. Levels of IFN- $\gamma$ and IL-4 were also measured by ELISA using the High Sensitivity ELISA Ready-SET-Go Kits (eBioscience, San Diego, Germany) according to manufacturer's instructions. TGF- $\beta$ was also quantified using the Duo Set ELISA Development kit mouse plasma TGF- $\beta 1$ (R\&D Systems, Wiesbaden-Nordenstadt, Germany). 
A

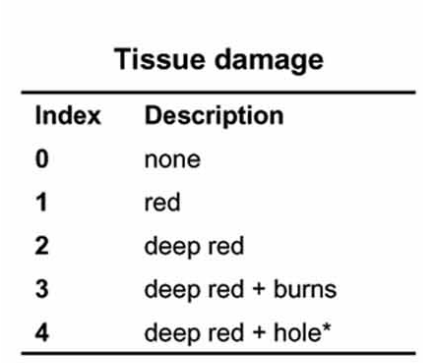

B

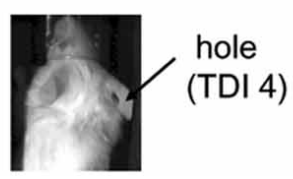

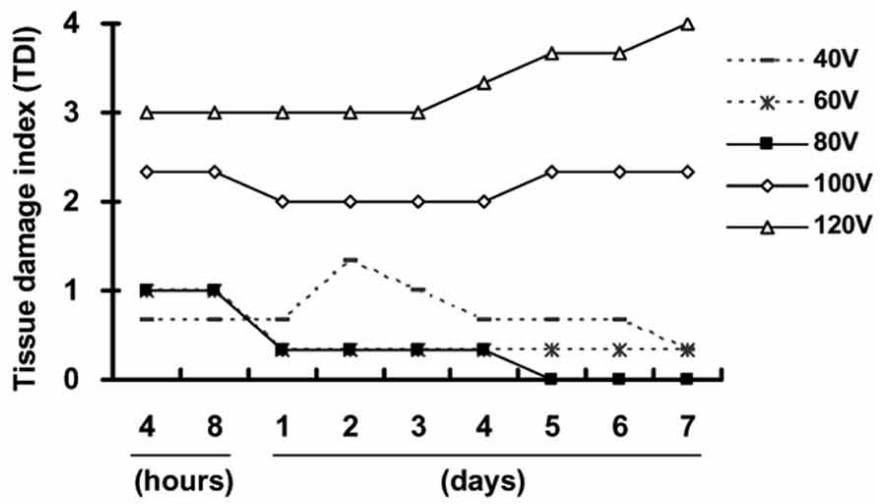

Time after DNA electroporation

Fig. (2). Analysis of the local tissue damage induced by EP using different voltages.

A. Tissue damage in mice after EP. DNA was applied into the ear pinna of DBA/2 mice and EPs were performed using the EP device which is described in Fig. (1). Different voltages varying from 40 to $120 \mathrm{~V}$ were used. The damage level was quantified using indexes evaluating local tissue damages at the ear pinna site as defined in the left table. It was monitored during 7 days following EP. $n=3$ in each group.

B. A representative mouse with a burned hole in the ear after EP by $120 \mathrm{~V}$. EP in the ear using a voltage of $120 \mathrm{~V}$ induced high tissue damage. This can be observed by the apparition at day 7 of a burned hole in the ear pinna of the mouse as shown on the photography.

In vitro re-stimulation and cytotoxicity assays. Two weeks after lacZ DNA immunization, mice were killed. Splenocytes were prepared and then re-stimulated in vitro for 5 days in RPMI medium containing $10 \%$ FCS and $0.5 \mu \mathrm{g} / \mathrm{ml}$ of the synthetic nonamer TPHPARIGL in $5 \times 10^{6} / \mathrm{mL}$. This peptide represents the naturally processed $\mathrm{H}-2 \mathrm{Ld}$-restricted CD8 T cell epitope of $\beta$-gal spanning amino acids 876-884. This peptide was synthesized by R Pipkorn (DKFZ, Heidelberg, Germany). Supernatants of these cultures were collected on day 2 or on day 5 for the determination respectively of IFN- $\gamma$ and IL- 4 by ELISA. Re-stimulated spleen cells were used as the effector cells to test their cytotoxic activity in a standard $4 \mathrm{~h}{ }^{51} \mathrm{Cr}$ release assay at different effector : target ratios against $5 \times 10^{3}{ }^{51} \mathrm{Cr}$-labeled P13.1 (lacZ $\left.{ }^{+}\right)$ and P815 (lacZ ${ }^{-}$) cells, respectively as described [67, 68]. The amount of ${ }^{51} \mathrm{Cr}$ released was measured in a gamma counter and the percentage of lysis was calculated from the formula:

((experimental cpm - spontaneous cpm)/(maximum cpm - spontaneous cpm) $\times 100$. Spontaneous release was always below $30 \%$.

\section{STATISTICS}

The statistical significance of results from experimental groups in comparison to control groups was determined by the Student's t test unless otherwise specified. All tests were two-tailed and $\mathrm{p}<0.05$ was considered to be statistically significant.

\section{RESULTS}

\section{Optimization of DNA EP to Skin}

All the EPs were performed using the ELGEN1000 DNA delivery system which is represented in Fig. (1) and using the parameters summarized in Table 1 . We performed a panel of experiments by testing different voltages $(40,60$, $80,100,120 \mathrm{~V} / \mathrm{cm})$ for DNA EP at the site of the ear pinna. First, we monitored the tissue damage at the site which has been electroporated. In order to evaluate such effects in a quantitative manner, we defined the tissue damage index (TDI) as indicated in Fig. (2A). EP of DNA using a low voltage $(80 \mathrm{~V}$ or lower) induced a transient and mild tissue inflammation corresponding to redness in ears which vanished within 1 week. The use of higher voltages (as $100 \mathrm{~V}$ and $120 \mathrm{~V}$ ) induced more severe irreversible tissue damages such as deep red spots and burns at the site of EP persisting during 3 days after EP. Thirty percent or $100 \%$ of the mice showed a punctured skin (Fig. 2B) at the site of EP when using $100 \mathrm{~V}$ or $120 \mathrm{~V}$ respectively (data not shown). Serious tissue damage was also seen when EP was performed at the flank skin when using $100 \mathrm{~V}$ and $120 \mathrm{~V}$ (data not shown). Tissue damage was still visible 1 year after EP (data not shown). We conclude that EP should be performed using a voltage lower than $100 \mathrm{~V}$.

We next analyzed the effect of EP on Ag expression following DNA plasmid injection. Mice were injected with a plasmid CMV-luciferase coding for the firefly luciferase at the ear pinna (i.e.) or at the flank skin (i.d.) in combination with EP (right) or not (left) as described in the schema of the Fig. (3A). The expression of the firefly luciferase as indication of the antigen expression was monitored during 1 week by in vivo imaging (Fig. 3B). Quantitative analysis of the measured signal showed that Ag expression improved by a factor of 10 in the ear pinna and by a factor of 100 in the flank skin after DNA application with EP when the three voltages of 80,100 and $120 \mathrm{~V}$ were used. In contrast, the use of 40 and $60 \mathrm{~V}$ during EP led to a lower improvement of antigen expression at the flank skin and no improvement at 
A

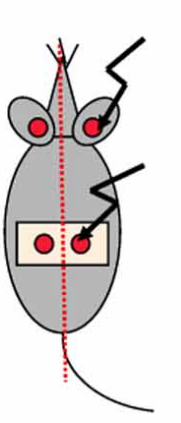

B

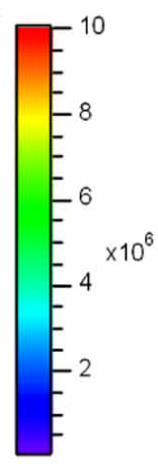

$40 \mathrm{~V}$

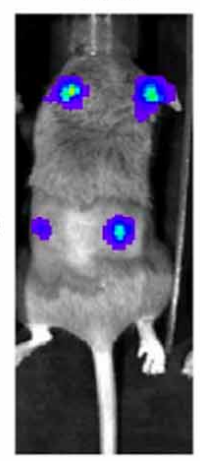

$60 \mathrm{~V}$

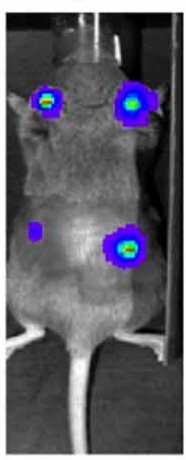

$$
\text { ( }
$$

.

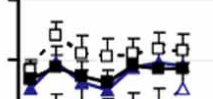

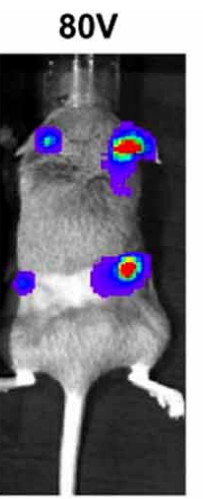
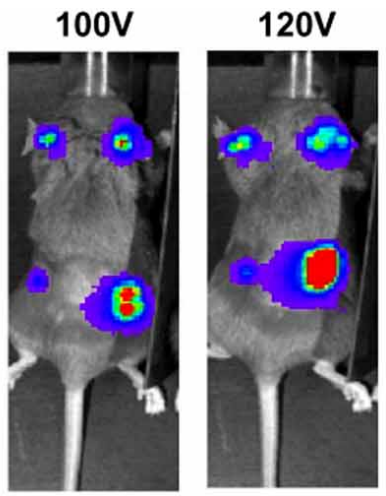

\begin{tabular}{|r|r|}
\hline & route EP \\
$-\Delta \cdot$ i.d. $\quad-$ \\
- i.d. $\quad+$ \\
$-\square$ i.e. $\quad-$ \\
- i.e. $\quad+$
\end{tabular}

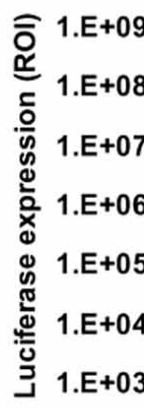

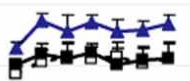

I. E.J.J.L. I.
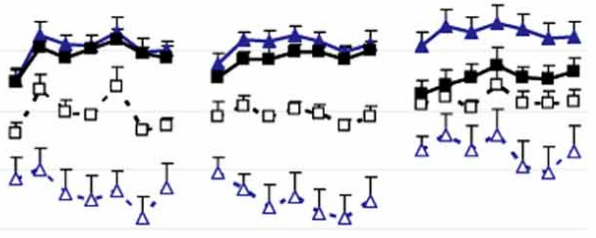

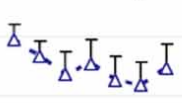

Fig. (3). Ag expression after DNA EP using different voltages.

A. DNA transfer into ear and flank skin. The plasmid CMV-luciferase encoding the firefly luciferase gene under the control of the CMV promoter was injected $(25 \mu \mathrm{g} / 50 \mu \mathrm{L})$ intradermally to the ear pinna and flank skin. And EP was performed (right side of the mouse) or not (left side).

B. In vivo luciferase expression. Using the experimental design indicated in A, DNA was applied to DBA/2 mice and electroporated using different voltages comprised between $40 \mathrm{~V}$ and $120 \mathrm{~V}$. Bioluminescent signal was monitored over 7 days with the IVIS100 imaging system using an exposure time of $10 \mathrm{~s}$. One representative mouse of each group ( $\mathrm{n}=3$ for each) is shown. Luciferase signal was quantified in pseudophoton unit $\left(\mathrm{p} / \mathrm{sec} / \mathrm{cm}^{2} / \mathrm{sr}\right)$ as described in material and methods. One representative experiment out of three is shown.

the ear pinna. These results showed that DNA EP using a voltage of 80,100 or $120 \mathrm{~V}$ efficiently improved Ag expression in the skin after DNA injection. We decided to use $80 \mathrm{~V}$ for all the further EPs.

\section{Long-term Ag Expression after DNA Injection and EP}

To analyze long-term effects on Ag expression after DNA injection combined with EP, mice were immunized with the plasmid CMV-luciferase. Left ear and flank skin were not electroporated whereas the right ones were (as indicated in Fig. 3A). Luciferase activity was monitored over 350 days after EP. We observed that EP improved the Ag expression at both application sites. An increase of antigen expression corresponding to factors between 50 and 500 was observed when vaccination was performed at the flank site. In contrast, the antigen expression was only increased by factors between 5 and 20 when the ear pinna was used as vaccination site (Fig. 4). Although we observed that the signals were 5 to 50 times higher at the site of the ear pinna as compared to the flank skin without EP, similar levels of Ag expression were obtained for both routes after DNA EP (Fig. 4).
High levels of Ag expression were seen for 2 weeks after DNA EP at both sites. After 4 weeks, Ag expression decreased by a factor of 10 to 100 , but maintained at a low but stable level during 350 days (Fig. 4). These results reveal that EP can be used to increase Ag expression for long terms.

\section{Humoral and Cellular Immune Responses after EP}

We then analyzed if EP can improve immune responses against the target $\mathrm{Ag}$ encoded by the plasmid in vivo. For these investigations, we used a DNA plasmid with the LacZ gene coding for bacterial beta-galactosidase ( $\beta$-gal). We applied this plasmid either to the ear pinna (i.e.) or to the flank skin (i.d.). Humoral responses were analyzed via ELISA, testing the levels of antibodies specific for the $\beta$-gal protein in the plasma of mice. EP induced an increase of anti- $\beta$-gal antibody levels by a factor 46 when immunization was performed at the flank skin. In contrast, the increase of the antibody titer towards $\beta$-gal was only increased by a factor of 5 when the ear pinna was used (Fig. 5A). However, a higher $\mathrm{Ab}$ titer was induced by DNA immunization at the ear pinna in comparison to the flank skin, no matter if EP was performed or not. 


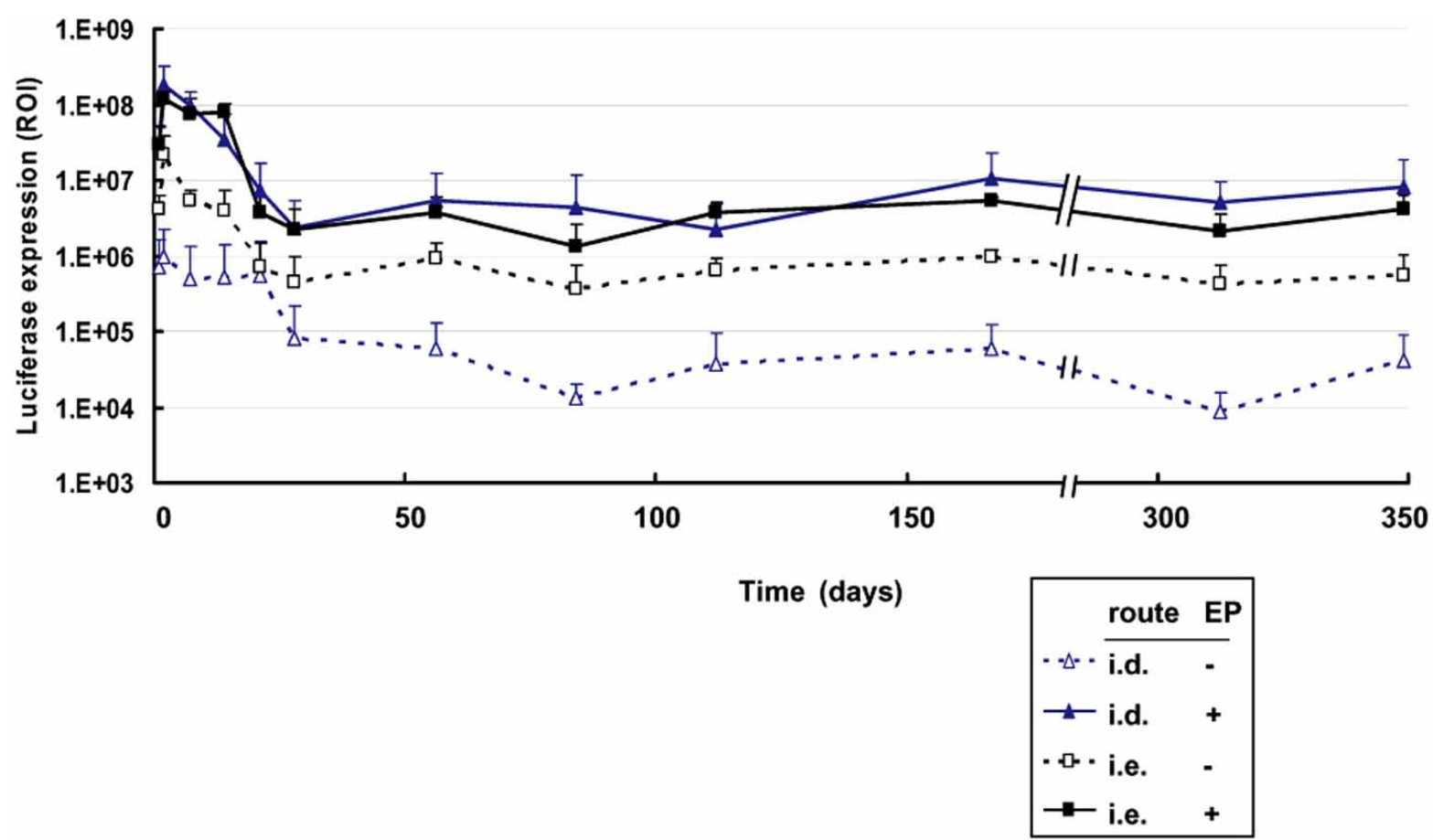

Fig. (4). Long-term Ag expression after DNA application at the flank skin or ear pinna without and with EP.

The plasmid CMV-luciferase $(25 \mu \mathrm{g} / 50 \mu \mathrm{L})$ was injected i.e. and i.d. to the ear and flank without (left) and with (right) EP in the same way as in Fig. (2). The only difference is that a voltage of $80 \mathrm{~V}$ was applied during the EP step. Bioluminescent signal was calculated in pseudophoton unit $\left(\mathrm{p} / \mathrm{sec} / \mathrm{cm}^{2} / \mathrm{sr}\right)$. Exposure time: $10 \mathrm{~s}$. DBA $/ 2$ mice, $\mathrm{n}=3$. Results of one representative experiment from three independent experiments leading to the similar observations are shown.

To test cellular immune responses, we analyzed the $\beta$-gal specific CD8 cytotoxic T lymphocyte (CTL) response in vitro using splenocytes from mice which have been immunized according to the different protocols. Ag specific cytotoxicity which was higher in case of DNA application into the ear pinna was significantly improved by EP at both application sites (Fig. 5B). Moreover, a significantly higher CTL response was observed using the ear pinna as vaccination route compared to the flank skin. To test the antigenspecific $\mathrm{T}$ cell cytokine responses, we performed restimulation assays by incubating splenocytes from immunized mice in vitro with an $\mathrm{H} 2$-Ld dominant peptide epitope derived from the $\beta$-gal protein. We observed that EP improved the IFN- $\gamma$ response by the re-stimulated splenocytes from mice immunized at the site of the ear pinna but not at the flank skin (Fig. 5C). In contrast, EP improved the production of IL-4 by re-stimulated splenocytes from mice immunized at the flank skin but not at the ear pinna (Fig. 5D).

These results demonstrate that EP improved both humoral and cellular immune responses after DNA application. $\mathrm{EP}$ at ear pinna favored a Th1 T cell mediated immune response (characterized by CTLs and high levels of IFN- $\gamma$ ). In contrast, EP of DNA at flank skin favored a Th2 type immune response characterized by the production of high levels of IL-4.

\section{Effects of EP on Anti-Tumor Effects Induced by DNA Vaccine}

Since DNA immunization followed by EP at the ear pinna induced stronger immune responses characterized by a
Th1 polarization, we tested this approach for anti-tumor effects in a therapeutic setting.

The tumor model is established by DA3-EpCAM tumor cell line which is a Balb/c mouse mammary carcinoma cell line DA3 transfected with human EpCAM gene. Tumors were induced by subcutaneous application of DA3-EpCAM cells. Once the tumor had a diameter of about $5 \mathrm{~mm}$ or more (after 7 days), mice were treated by application of plasmid DNA encoding the human EpCAM gene without or with EP according to the experimental schema indicated in Fig. (6A). Tumor growth was followed during and after treatments. Tumor growth was significantly reduced by application of the plasmid encoding the EpCAM gene and electroporation (Fig. 6B). The tumors were even eliminated in $20 \%$ of the mice after the 4th DNA application of this plasmid without EP as indicated in the Fig. (6B) bottom. The combination of EP with application of the plasmid DNA led to an increase of the percentage of tumor-free mice to $60 \%$. In contrast, none of the mice treated by applications of irrelevant mock DNA (not leading to the expression of the EpCAM antigen) became tumor-free.

DA3-EpCAM cells, when cultured in vitro, secrete constitutively transforming growth factor-beta (TGF- $\beta$ ) in the culture supernatant (data not shown). This led us to analyze TGF- $\beta$ levels in the peripheral blood of mice after DNA treatments. Results from Fig. (6C) show a significant downregulation of TGF- $\beta$ level in the blood when DNA vaccination was combined with EP. 
A

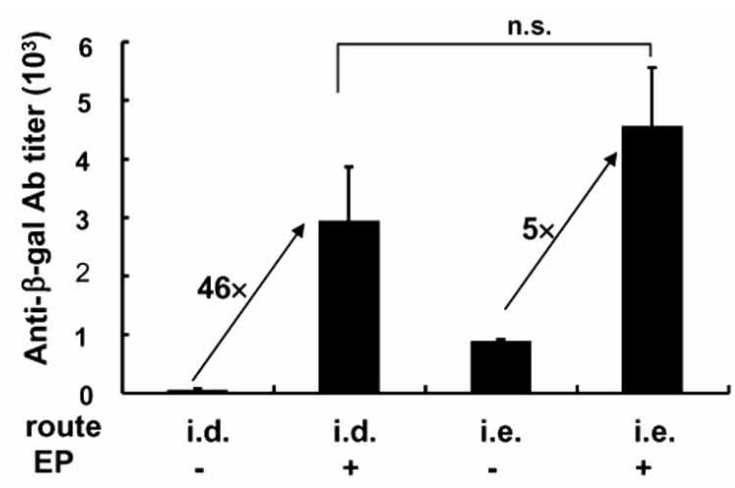

B

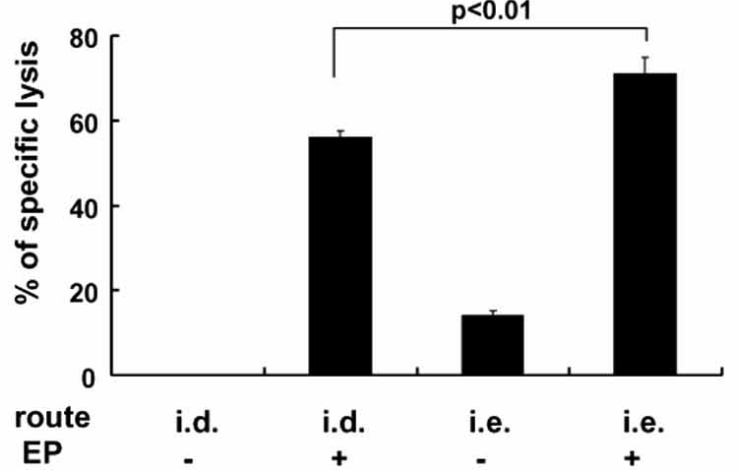

C
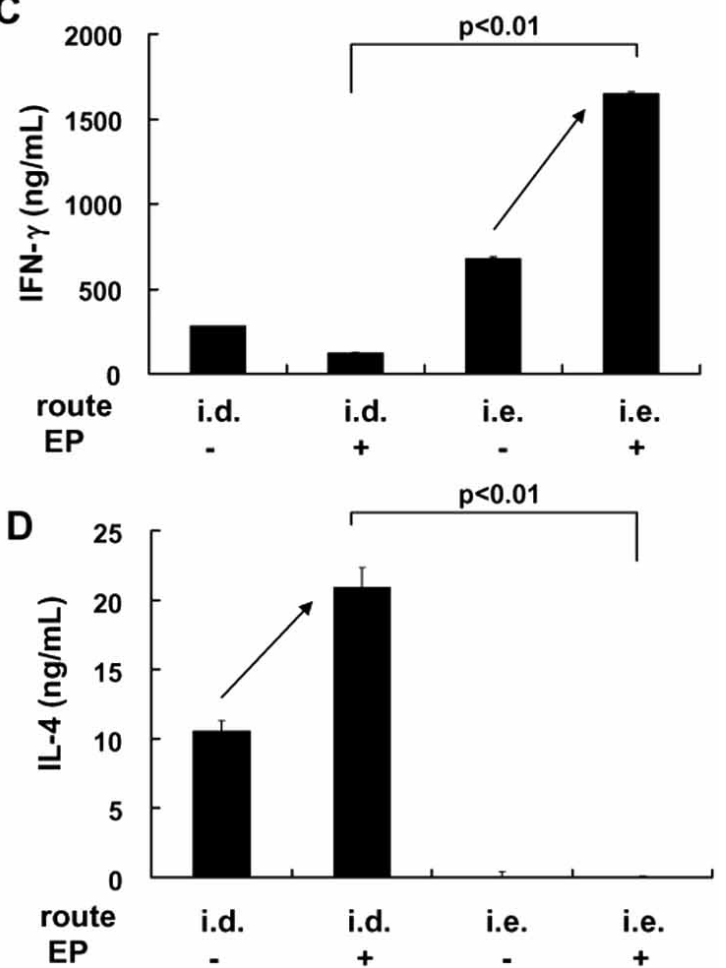

Fig. (5). Humoral and cell-mediated immune responses after DNA application at the flank site or at the ear pinna eventually followed by EP. A. Humoral response. DBA/2 mice $(\mathrm{n}=3)$ were immunized i.e. or i.d. with the plasmid pCMV SPORT- $\beta \mathrm{gal}(25 \mu \mathrm{g} / 50 \mu \mathrm{L}) \mathrm{without}$ or with EP $(80 \mathrm{~V})$. Bloods were collected at day 14 after DNA vaccination. Plasma were then prepared and analyzed by ELISA for anti- $\beta$-gal $\mathrm{Ab}$ responses $(\mathrm{IgG}+\mathrm{M})$. One of 3 independent experiments is shown. B. Cell-mediated immune responses. Mice were sacrificed at day 14 after DNA immunization. Spleens were taken out and re-stimulated for 5 days in vitro with $0.5 \mu \mathrm{g} / \mathrm{mL}$ TPHPARIGL peptide (H2-Ld epitope) and analyzed for cytotoxicity by a standard $4 \mathrm{~h}^{51} \mathrm{Cr}$ release assay using lac $\mathrm{Z}^{+}$tumor cells (P13.1) and lacZ tumor cells (P815) as target cells. An effector to target ratio of 100:1 was respected. One of three independent experiments showing similar results is shown. C and D. Cytokine production by splenocytes after in vitro re-stimulation. Supernatants of culture from re-stimulated splenocytes (as described in Fig. 4B) were collected at day 2 for IFN- $\gamma$ analysis (C) and at day 5 for IL-4 determination (D). The 2 cytokines were quantified by ELISA. One representative experiment from three is shown.

To analyze possible immunity against the parental tumor cell line DA3 after DNA treatments to DA3-EpCAM tumors, the DA3-EpCAM tumor bearing mice were re-challenged with DA3 cells at day 59 as shown in the Fig. (7A). We observed that DA3 tumor growth was significantly reduced in the group of mice which had received an injection at the ear pinna of the EpCAM encoding plasmid combined with EP in comparison to the group of mice that were immunized with this DNA without EP or with a vector control plasmid. No significant DA3 tumor retardation was observed in the group of mice treated with EpCAM without EP in comparison to mice treated with the mock DNA plasmid.

Taken together, these results provide evidence for the efficiency of therapeutic antitumor treatment when applying xenogeneic DNA vaccination at the ear pinna in combination with EP. Established DA3-EpCAM tumors were shown to regress and, upon re-challenge with DA3 tumor cells, there was growth retardation only in the group of EpCAM DNA EP treated mice. This immunization protocol thus induced immunity not only against the tumor cells with xenogeneic EpCAM expression but also cross-induced immunity against the parental tumor cells, possibly via breaking tolerance.

\section{DISCUSSION}

In this study, we combined DNA injection to the skin with EP. We report that such a vaccination strategy led to improved cellular immunity toward the antigen encoded by the plasmid. Of great importance was not only EP but also the site of immunization. The ear pinna was superior to flank skin and provided a Th1 polarized response with a strong anti-tumor immunity.

In this study, we used an EP-based delivery system using the ELGEN1000 device that has been developed by Inovio during the MOLEDA project. It is made of a pulse controller connected to 2 tweezers electrodes. It is designed for human applications by transferring small molecules including genetic materials and therapeutic drugs to certain tissues. Clinical trials (phase I/II) have proven safety, tolerability and immunological reactions in human [69-72]. EP has proven to be a highly effective technique for the in vivo delivery of genes to a number of solid tissues. In this study, we demonstrate for the first time a similar effect for the tissue of ear pinna. 

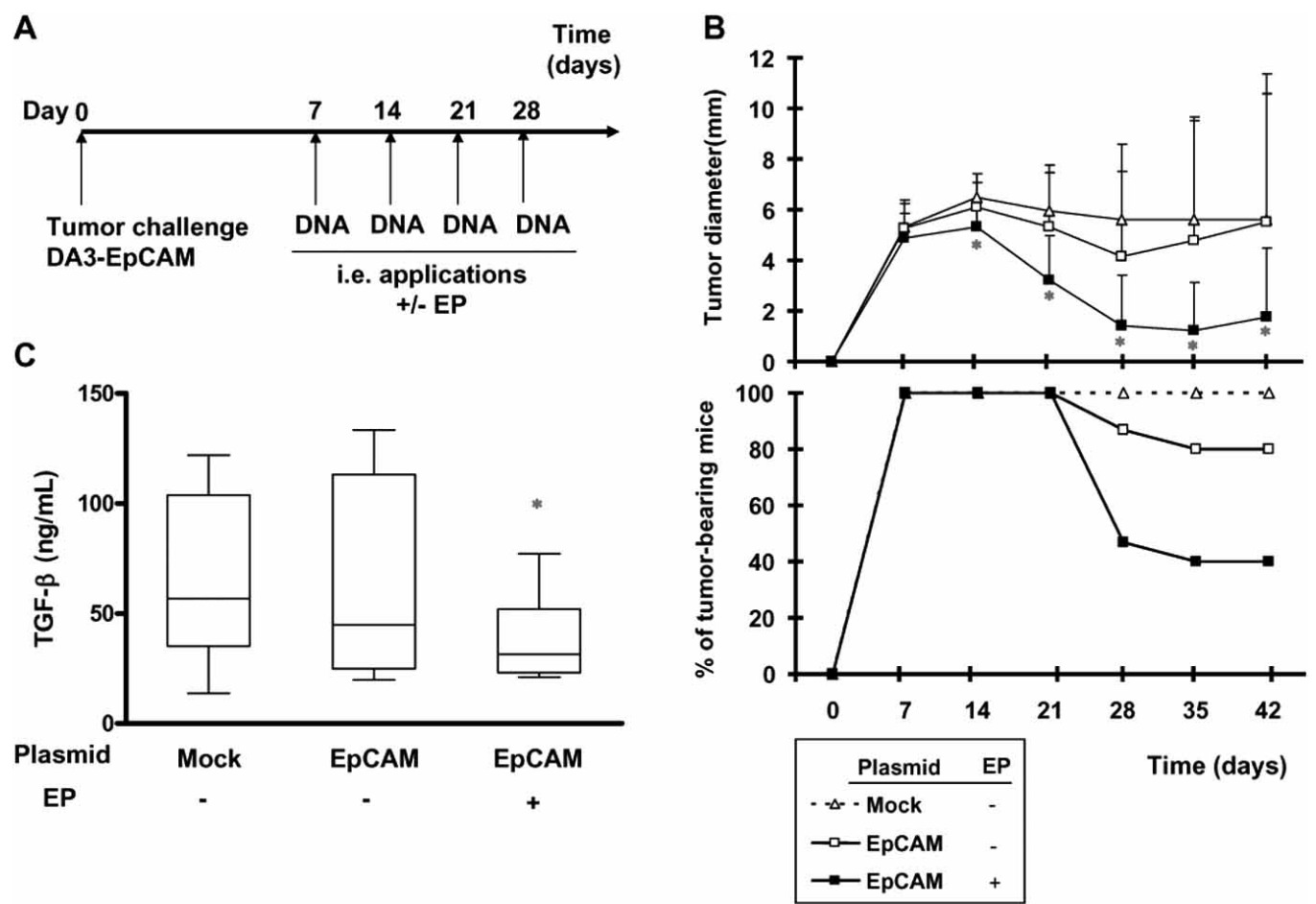

Fig. (6). Anti-tumor effects induced by EP in a therapeutic tumor model.

A. Experimental protocol. Balb/c mice $(n=13 \sim 15)$ were inoculated s.c. with $1 \times 10^{7}$ DA3-EpCAM cells. One week later, DNA encoding the human EpCAM gene under the CMV promoter was applied 4 times without and with EP respecting 1 week interval $(50 \mu \mathrm{g} / 50 \mu \mathrm{L}$ DNA between each immunization). The pTandem1 vector was used as a negative control (Mock DNA).

B. Therapeutic effects of DNA treatments. DA3-EpCAM tumor growth was followed and is represented as tumor diameter (top). The percentage of tumor-bearing mice was calculated for each group during the experiment (bottom). * Compared to the Mock and EpCAM i.e. groups, $\mathrm{p} \leq 0.05$.

C. Peripheral TGF- $\boldsymbol{\beta}$ levels. Plasma from DA3-EpCAM tumor bearing mice were taken at day 49 after tumor implantation. Concentrations of TGF- $\beta$ were defined by ELISA. * Compared to the Mock and EpCAM i.e. groups, $\mathrm{p} \leq 0.05$.

To enhance the level of gene expression from plasmids administrated into tissues, the use of optimal EP parameters is critical. If conditions are too harsh, severe tissue damage with extensive cell death can occur. Since gene expression and protein production from plasmids are dependent on viable cells, it is critical that the majority of the cells being transfected are not killed. Therefore, the optimal EP conditions are a subtle balance between enhancing permeability without causing extensive cell death and tissue trauma. Many studies reported that EP could damage the target tissue depending on the electric parameter associated with the EP $[69,73-76]$. We defined in this study that EP of DNA at the ear pinna site of mice is optimally performed using $80 \mathrm{~V}$ with the ELGEN1000 DNA delivery system.

What was remarkable is that, by combining EP and DNA, a relatively long-term stable Ag expression was induced in mice. Gene expression was maintained for a long time since the signal could still be detected after 350 days, a time which corresponds to the life-time of a mouse. This might be explained by the long-term existence of the DNA vector in host cells or integration of the plasmid DNA into hosts chromosomal DNA. There are only two published studies examining the potential for integration after EPmediated DNA delivery [77, 78]. For conventional DNA delivery, the risk of integration for causing an oncogenic event was observed to be low [79]. The use of a transduced firefly luciferase gene allowed a quick and very sensitive determination of protein expression in vivo since there is no endogenous luciferase enzyme activity in mammalian tissues. The level of Ag expression is an important determinant for the magnitude of an immune response to DNA vaccines. Also, however, the induction of an inflammatory response, due to the physical stimulation of skin cells by EP, might be crucial for enhancing immune responses [80]. This undefined adjuvant effect might be possibly mediated through local minor tissue damage and release of inflammatory factors $[79,81,82]$. Recent data suggest that in addition to enhancing gene delivery, EP provides adjuvant-like effects [82, 83]. Several reports have shown that the local effect by EP is responsible for the generation of an inflammatory environment with immune cell infiltration. The migration of these cells seems essential to initiate an adequate immune response to the DNA vaccine $[84,85]$. Previous studies using bupivacaine to enhance immune responses to DNA vaccines [86] suggested that muscle damage / inflammation is important for enhancing immune responses [58, 74, 87]. In another study, Nishijima et al. [88] reported that disruption of the skin barrier results in epidermal Langerhans cell activation as vigorous antigen presenters for $\mathrm{T}$ helper cells. 
A

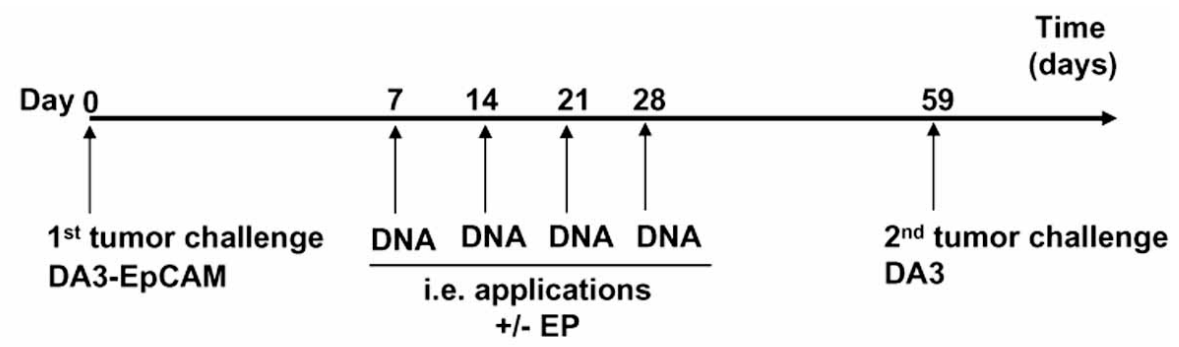

B

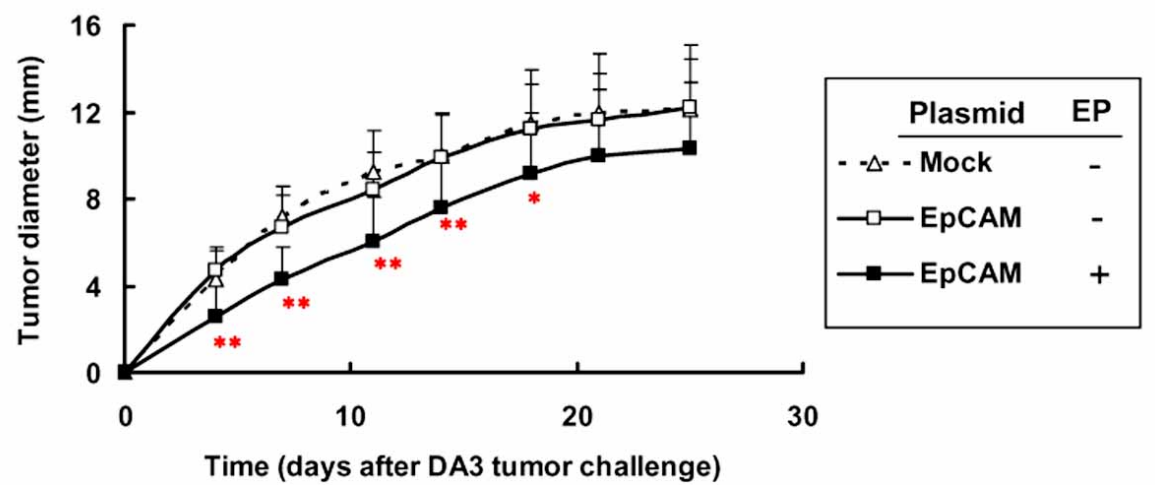

Fig. (7). Cross anti-tumor activity generated by EP.

A. Experimental protocol. DA3-EpCAM tumor bearing mice were therapeutically treated by i.e. immunization with the DNA plasmid encoding the human EpCAM gene using EP or not or with the control plasmid as described in Fig. (6). All the animals were challenged at day 59 by a s.c. inoculation of $1 \times 10^{7} \mathrm{DA} 3$ cells.

B. DA3 tumor growth. Tumor growth was monitored by measuring the diameter of the tumor corresponding to the DA3 cell line during 42 days starting from the $2^{\text {nd }}$ tumor challenge. $*$ Compared to the Mock and EpCAM i.e. groups, $\mathrm{p}<0.05$; **Compared to the Mock and EpCAM i.e. groups, $\mathrm{p}<0.01$.

A recent study [89] reported that EP of skeletal muscles without any application of DNA induces an inflammatory process associated with recruitment and activation of a danger-like pro-inflammatory pathway. These data sustain the idea that the immune responses mounted against the antigen may not only be due to the foreignness of the transfected gene but also to the danger signals associated with the delivery process [90]. Therefore, the efficacy of naked DNA vaccines delivered by EP resides in the strong stimulation of immunity at the EP site. It has also been observed that EP causes cellular infiltration into the electroporated tissue. This might be very important for generating an immune response following DNA immunization [58] since the transient inflammation associated with EP may provide an ideal environment for generation of immune responses to encoded antigens $[58,91]$. Thus, the mechanisms by which EP enhances immune responses to DNA vaccines may be a combination of increased gene expression and of generated proinflammatory environment.

In vivo gene delivery by EP has been demonstrated to be efficient for introducing DNA also into mouse skin [92, 93]. In most cases of small animal experimentation, i.d. immunization is applied to the abdominal or flank skin. We propose that ear pinna is a more attractive alternative for DNA immunization. It is a very special site and form of skin. One of the advantages might be the special structure of ear pinna which contains two layers of epidermis and dermis - separated by a cartilage - rich in professional APCs. In a previous study we provide evidence that CD11c DCs in the ear pinna are essential for the immune responses generated [94]. The superiority of the ear pinna as a vaccination site is ascribed to its unique immunological features that focus the concentration of proceeded antigens in a restricted area, which is connected to a major draining lymph node. It is thought that the concentration of processed antigens results in an enhanced stimulation of T lymphocytes by antigen-loaded DCs [95]. Intradermal DNA vaccination into the ear pinna route has been reported to produce high levels of neutralizing antibodies against rabies virus in dogs [96]. We observed in this study that EP augments immune responses to DNA vaccines. Antibody titers were augmented greatly as compared to injection of DNA vaccine without EP. T cell responses were also significantly enhanced with regard to IFN- $\gamma$ production and CTL killing activity.

It has been shown that in vivo EP can increase DNA uptake by cells at the site of injection $[29,83]$, leading to increased Ag expression [97-99]. Although the exact mechanism has yet to be elucidated, the Ag expression allows induction of immune responses through MHC-I and/or MHCII pathways. In either case, DCs and other APCs play a critical role in activating adaptive immunity. They must acquire the antigen to be delivered to the tissue-draining lymph nodes for priming of $\mathrm{CD}^{+}$cytotoxic T-lymphocytes (CTL) and the activation of $\mathrm{CD}^{+}$helper T-lymphocytes. Direct priming of CTL may be facilitated through DCs endogenously expressing antigen. DCs may also acquire antigen exogeneously through MHC I cross-presentation by various means including direct acquisition from dead or dying cells $[100,101]$. DCs may also acquire secreted antigen to be displayed through either MHC class I and/or II pathways [102]. 
Although enhancement of immune responses by EP is probably also due to an increase of antigen expression by other cells such as keratinocytes, we believe that DCs play a major role [94] in the induction of a strong immune response at the ear pinna site either by cross-priming or by direct priming. DCs very probably migrate to the draining lymph nodes and trigger the immune response. The role of DCs has been demonstrated during EP-based vaccination. DCs from draining lymph nodes were shown to contain DNA originating from the injection site [103].

Our data show also that the ear pinna route skews the immune response towards Th1 whereas the application of DNA to the skin from the flank skews the immune response towards Th2. Gene gun immunization has been shown to skew immune responses towards Th2. In contrast, EP is more efficient for induction of Th1 immune responses [104106]. Consequently, the use of EP as a method of antigen delivery and ear pinna as the site of DNA application might explain the Th1 polarization of the immune response. Further studies need to be performed in order to identify the cells that are involved and understand why the use of this route leads to the generation of such a strong Th1 type cellular immune response.

Mechanisms of tolerance and immune escape are drawbacks to cancer vaccination. TGF- $\beta$, one of the immunosuppressive cytokine which is often secreted in large amounts by malignant cells such as the DA3 tumor cell line used in this study. This molecule acts on nontransformed cells present in the tumor mass as well as on distal cells in the host to suppress antitumor immune responses creating an environment of immune tolerance [107]. A strong immune reactivity is then required to reverse the immunosuppressive effects induced by this cytokine. We observed in this study that EP after DNA injection also down-regulated peripheral TGF- $\beta$ levels in tumor-bearing mice. It is not clear how the downregulation was achieved. It could be the outcome from the inhibition of tumor growth by DNA EP, because less tumor derived suppressive factors might be secreted by smaller tumors.

The goal of active therapeutic vaccination against cancer is to induce a strong effective immunity against tumor cells and to establish immunological memory that is able to maintain continuous surveillance against emergent cancer cells. EP was found to improve the kinetics of immune responses by requiring less time than conventional injection to reach a maximal immune response [108, 109] and favoring the induction of long-term memory [110] but also the consistency of the immune responses induced when compared with injection without EP. Because these initial results seem promising, vaccination trials based on ear pinna immunization with autologous irradiated tumor cells electroporated with DNA should be considered for the future. Efficacy and tolerability of EP was demonstrated in phase I clinical trials performed in collaboration with some companies [111] where in some studies the EP technology was used for intratumoral delivery of plasmid DNA [112]. The increase of knowledge about immune responses generated from the site of the ear pinna and the potential of DNA EP delivery for generating strong cellular immunity give hope to the field of DNA-based cancer therapy.
In conclusion, the results presented here show that the ear pinna is a privileged site for DNA EP. Compared to traditional DNA application to the flank skin in mice, the strategy of DNA EP at the ear pinna induced similar Ag expression but led to the induction of very strong cellular immunity toward the Ag encoded by the plasmid with a strong Th1 polarization. By this method, therapeutic anti-tumor effects were also achieved in a mouse tumor model. Such increases in DNA vaccine potency provide encouragement that such an immunization could be tested in large animals.

\section{ACKNOWLEDGEMENTS}

This project has been performed within the frame of the project MOLEDA (acronym standing for Molecular Optimization of Laser / Electrotransfer DNA Administration into muscle and skin for gene therapy) sponsored by the European Commission during the research program FP6. We are particularly grateful to Annette Arnold for her technical assistance. We acknowledge also the DAAD (German Academic Exchange Service) for support of Jing Ni during her $\mathrm{PhD}$ thesis.

\section{REFERENCES}

[1] Tang DC, DeVit M, Johnston SA. Genetic immunization is a simple method for eliciting an immune response. Nature 1992; 356(6365): 152-4.

[2] Ulmer JB, Sadoff JC, Liu MA. DNA vaccines. Curr Opin Immunol. 1996; 8(4): 531-6.

[3] Sedegah, M, Hedstrom R, Hobart P, Hoffman SL. Protection against malaria by immunization with plasmid DNA encoding circumsporozoite protein. Proc Natl Acad Sci USA 1994; 91: 986670.

[4] Polack, FP, Lee SH, Permar S, et al. Successful DNA immunization against measles: neutralizing antibody against either the hemagglutinin or fusion glycoprotein protects rhesus macaques without evidence of atypical measles. Nat Med 2000; 6: 776-81.

[5] Ulmer JB, Donnelly JJ, Parker SE, et al. Heterologous protection against influenza by injection of DNA encoding a viral protein. Science 1993; 259: 1745-49.

[6] Davis HL, Michel ML, Whalen RG. DNA-based immunization induces continuous secretion of hepatitis B surface antigen and high levels of circulating antibody. Hum Mol Genet 1993; 2: 184751 .

[7] Conry, RM, LoBuglio AF, Kantor J, et al. Immune response to a carcinoembryonic antigen polynucleotide vaccine. Cancer Res 1994; 54: 1164-68.

[8] Hawkins, RE, Zhu D, Ovecka M, et al. Idiotypic vaccination against human B-cell lymphoma: rescue of variable region gene sequences from biopsy material for assembly as single-chain Fv personal vaccines. Blood 1994; 83 : 3279-88.

[9] Ciernik, IF, Berzofsky JA, Carbone DP. Induction of cytotoxic T lymphocytes and antitumor immunity with DNA vaccines expressing single T cell epitopes. J Immunol 1996; 156: 2369-75.

[10] Spellerberg, MB, Zhu D, Thompsett A, King CA, Hamblin TJ, Stevenson FK. DNA vaccines against lymphoma: promotion of anti-idiotypic antibody responses induced by single chain Fv genes by fusion to tetanus toxin fragment C. J Immunol 1997; 159: 188592.

[11] Hsu CH, Chua KY, Tao MH, et al. Immunoprophylaxis of allergen-induced immunoglobulin E synthesis and airway hyperresponsiveness in vivo by genetic immunization. Nat Med 1996; 2: 54044.

[12] Wildbaum, G. Nahir MA, Karin N. Beneficial autoimmunity to proinflammatory mediators restrains the consequences of selfdestructive immunity. Immunity 2003; 19: 679-88.

[13] Youssef S, Maor G, Wildbaum G, Grabie N, Gour-Lavie A, Karin N. C-C chemokine-encoding DNA vaccines enhance breakdown of tolerance to their gene products and treat ongoing adjuvant arthritis. J Clin Invest 2000; 106: 361-71. 
[14] Powell K. DNA vaccines--back in the saddle again? Nat Biotechnol 2004; 22(7): 799-801.

[15] Lorenzen N, LaPatra SE. DNA vaccines for aquacultured fish. Rev Sci Tech 2005; 24(1): 201-13

[16] Bergman PJ, Camps-Palau MA, McKnight JA, et al. Development of a xenogeneic DNA vaccine program for canine malignant melanoma at the Animal Medical Center. Vaccine 2006; 24(21): 45825 .

[17] Bergman PJ, McKnight J, Novosad A, et al. Long-term survival of dogs with advanced malignant melanoma after DNA vaccination with xenogeneic human tyrosinase: a phase I trial. Clin Cancer Res 2003; 9(4): 1284-90.

[18] Liao JC, Gregor P, Wolchok JD, et al. Vaccination with human tyrosinase DNA induces antibody responses in dogs with advanced melanoma. Cancer Immun 2006; 6: 8 .

[19] Therapy Clinical Trials Worldwide - Chart\&Table Keyword: Vectors (Updated March 2009) available from http: //www.wiley.co.uk/genmed/clinical/Gene.

[20] Bodles-Brakhop AM, Draghia-Akli R. DNA vaccination and gene therapy: optimization and delivery for cancer therapy. Expert Rev Vaccines 2008; 7(7): 1085-101.

[21] van Drunen Littel-van den Hurk S, Loehr BI, Babiuk LA. Immunization of livestock with DNA vaccines: current studies and future prospects. Vaccine 2001; 19(17-19): 2474-9.

[22] Gurunathan S, Klinman DM, Seder RA. DNA vaccines: immunology, application, and optimization. Annu Rev Immunol 2000; 18: 927-74.

[23] Donnelly JJ, Wahren B, Liu MA. DNA vaccines: progress and challenges. J Immunol 2005; 175: 633-9.

[24] Wang R, Doolan DL, Le TP, et al. Induction of antigen-specific cytotoxic $\mathrm{T}$ lymphocytes in humans by a malaria DNA vaccine. Science 1998; 282(5388): 476-80.

[25] Calarota S, Bratt G, Nordlund S, et al. Cellular cytotoxic response induced by DNA vaccination in HIV-1-infected patients. Lancet 1998; 351(9112): 1320-5.

[26] MacGregor RR, Boyer JD, Ugen KE, et al. First human trial of a DNA-based vaccine for treatment of human immunodeficiency virus type 1 infection: safety and host response. J Infect Dis 1998; 178(1): 92-100.

[27] Wang R, Epstein J, Baraceros FM, et al. Induction of CD4+ T celldependent CD8+ type 1 responses in humans by a malaria DNA vaccine. Proc Natl Acad Sci USA 2001; 98: 10817-22.

[28] Stevenson FK, Rice J, Ottensmeier CH, Thirdborough SM, Zhu D. DNA fusion gene vaccines against cancer: from the laboratory to the clinic. Immunol Rev 2004; 199: 156-80.

[29] Widera G, Austin M, Rabussay D, et al. Increased DNA vaccine delivery and immunogenicity by electroporation in vivo. J Immunol 2000; 164: 4635-40.

[30] Patil SD, Rhodes DG, Burgess DJ. DNA-based therapeutics and DNA delivery systems: a comprehensive review. AAPS J 2005; 7 : E61-77.

[31] Hengge UR, Chan EF, Foster RA, Walker PS, Vogel JC. Cytokine gene expression in epidermis with biological effects following injection of naked DNA. Nat Genet 1995; 10: 161-66.

[32] Yang NS, Burkholder J, Roberts B, Martinell B, McCabe D. In vivo and in vitro gene transfer to mammalian somatic cells by particle bombardment. Proc Natl Acad Sci USA 1990; 87: 9568-72.

[33] Ciernik IF, Krayenbühl BH, Carbone DP. Puncture-mediated gene transfer to the skin. Hum Gene Ther 1996; 7: 893-99.

[34] McAllister DV, Allen MG, Prausnitz MR. Microfabricated microneedles for gene and drug delivrey. Annu Rev Biomed Eng 2000; 2: 289-313.

[35] Mikszta JA, Alarcon JB, Brittingham JM, Sutter DE, Pettis RJ, Harvey NG. Improved genetic immunization via micromechanical disruption of skin-barrier function and targeted epidermal delivery. Nat Med 2002; 8: 415-19.

[36] Badiavas E, Mehta PP, Falanga V. Retrovirally mediated gene transfer in a skin equivalent model of chronic wounds. J Dermatol Sci 1996; 13: 56-62.

[37] Lu B, Federoff H, Wang Y, Goldsmith LA, Scott G. Topical application of viral vectors for epidermal gene transfer. J Invest Dermatol 1997; 108: 803-8.

[38] Hirao LA, Wu L, Khan AS, Satishchandran A, Draghia-Akli R, Weiner DB. Intradermal/subcutaneous immunization by electroporation improves plasmid vaccine delivery and potency in pigs and rhesus macaques. Vaccine 2008; 26: 440-8.
[39] Capone S, Zampaglione I, Vitelli A, et al. Modulation of the immune response induced by gene electrotransfer of a hepatitis $\mathrm{C}$ virus DNA vaccine in nonhuman primates. J Immunol 2006; 177 ; 7462-71.

[40] Verstrepen BE, Bins AD, Rollier CS, et al. Improved HIV-1 specific T-cell responses by short-interval DNA tattooing as compared to intramuscular immunization in non-human primates. Vaccine 2008; 26: 3346-51

[41] Pokorna D, Rubio I, Muller M. DNA-vaccination via tattooing induces stronger humoral and cellular immune responses than intramuscular delivery supported by molecular adjuvants. Genet Vaccines Ther 2008; 6: 4

[42] Kim D, Hoory T, Monie A, Ting JP, Hung CF, Wu TC. Enhancement of DNA vaccine potency through coadministration of CIITA DNA with DNA vaccines via gene gun. J Immunol 2008; 180: 7019-27.

[43] Li S. Electroporation gene therapy: new developments in vivo and in vitro. Curr Gene Ther 2004; 4(3): 309-16.

[44] Wells DJ. Gene therapy progress and prospects: electroporation and other physical methods. Gene Ther. 2004; 11(18): 1363-9.

[45] Andre F, Mir LM. DNA electrotransfer: its principles and an updated review of its therapeutic applications. Gene Ther 2004; 11 (Suppl 1): S33-42.

[46] Rols MP. Mechanism by which electroporation mediates DNA migration and entry into cells and targeted tissues. Methods Mol Biol 2008; 423: 19-33.

[47] Bureau MF, Gehl J, Deleuze V, Mir LM, Scherman D. Importance of association between permeabilization and electrophoretic forces forintramuscular DNA electrotransfer. Biochim Biophys Acta 2000; 1474(3): 353-59.

[48] Satkauskas S, Bureau MF, Puc M, et al. Mechanisms of in vivo DNA electrotransfer: respective contributions of cell electropermeabilization and DNA electrophoresis. Mol Ther 2002; 5(2): 133-40.

[49] Satkauskas S, André F, Bureau MF, Scherman D, Miklavcic D, Mir LM. Electrophoretic component of electric pulses determines the efficacy of in vivo DNA electrotransfer. Hum Gene Ther 2005; 16(10): 1194-201.

[50] Liu F, Heston S, Shollenberger LM, et al. Mechanism of in vivo DNA transport into cells by electroporation: electrophoresis across the plasma membrane may not be involved. J Gene Med 2006; 8(3): 353-61

[51] Murtaugh MP, Foss DL. Inflammatory cytokines and antigen presenting cell activation. Vet Immunol Immunopathol. 2002; 87(3-4): 109-21.

[52] Liu J, Kjeken R, Mathiesen I, Barouch DH. Recruitment of antigen-presenting cells to the site of inoculation and augmentation of human immunodeficiency virus type 1 DNA vaccine immunogenicity by in vivo electroporation. J Virol 2008; 82(11): 5643-9.

[53] Wolff JA, Malone RW, Williams P, et al. Direct gene transfer into mouse muscle in vivo. Science 1990; 247: 1465-8.

[54] Deck RR, DeWitt CM, Donnelly JJ, Liu MA, Ulmer JB. Characterization of humoral immune responses induced by an influenza hemagglutinin DNA vaccine. Vaccine 1997; 15: 71-78.

[55] Donnelly JJ, Friedman A, Martinez D, et al. Preclinical efficacy of a prototype DNA vaccine: Enhanced protection against antigenic drift in influenza virus. Nat Med 1995; 1: 583-87.

[56] Okuda K, Ihata A, Watabe S, et al. Protective immunity against influenza A virus induced by immunization with DNA plasmid containing influenza M gene. Vaccine 2001; 19: 3681-91.

[57] Ulmer JB, Deck RR, DeWitt CM, Friedman A, Donnelly JJ, Liu MA. Protective immunity by intramuscular injection of low doses of influenza virus DNA vaccines. Vaccine 1994; 12: 1541-44.

[58] Babiuk S, Baca-Estrada M, Babiuk LA, Ewen C, Foldvari M. Cutaneous vaccination: The skin as an immunologically active tissue and the challenge of antigen delivery. J Control Release 2000; 66: 199-214.

[59] Puri N, Weyand EH, Abdel-Rahman SM, Sinko PJ. An investigation of the intradermal route as an effective means of immunization for microparticulate vaccine delivery systems. Vaccine 2000; 18(23): 2600-12.

[60] Banchereau J, Steinman RM. Dendritic cells and the control of immunity. Nature 1998; 392: 245-52.

[61] Peachman KK, Rao M, Alving CR. Immunization with DNA through the skin. Methods 2003; 31: 232-42.

[62] Donnelly JJ, Liu MA, Ulmer JB. Antigen presentation and DNA vaccines. Am J Respir Crit Care Med 2000; 162: S190-3. 
[63] Stoitzner P, Tripp CH, Eberhart A, et al. Langerhans cells crosspresent antigen derived from skin. Proc Natl Acad Sci USA 2006; 103: 7783-8.

[64] Jurianz K, von Hoegen P, Schirrmacher V. Superiority of the ear pinna over a subcutaneous tumour inoculation site for induction of a Th1-type cytokine response.Cancer Immunol Immunother 1998; 45: 327-33.

[65] Forg P, von Hoegen P, Dalemans W, Schirrmacher V. Superiority of the ear pinna over muscle tissue as site for DNA vaccination. Gene Ther 1998; 5: 789-97.

[66] Schirmacher V, Forg P, Dalemans W, et al. Intra-pinna anti-tumor vaccination with self-replicating infectious RNA or with DNA encoding a model tumor antigen and a cytokine. Gene Ther 2000; 7 : $1137-47$

[67] Kruger A, Schirrmacher V, von Hoegen P. Scattered micrometastases visualized at the single-cell level: detection and re-isolation of lacZ-labeled metastasized lymphoma cells. Int J Cancer 1994; 58: 275-84.

[68] von Hoegen P, Weber E, Schirrmacher V. Modification of tumor cells by a low dose of Newcastle disease virus. Augmentation of the tumor-specific T cell response in the absence of an antiviral response. Eur J Immunol 1988; 18: 1159-66.

[69] Gronevik E, von Steyern FV, Kalhovde JM, Tjelle TE, Mathiesen I. Gene expression and immune response kinetics using electroporation-mediated DNA delivery to muscle. J Gene Med 2005; 7: 218-27.

[70] Rabussay D. Applicator and electrode design for in vivo DNA delivery by electroporation. Methods Mol Biol 2008; 423: 35-59.

[71] Tjelle TE, Rabussay D, Ottensmeier C, Mathiesen I, Kjeken R. Taking electroporation-based delivery of DNA vaccination into humans: a generic clinical protocol. Methods Mol Biol 2008; 423 : 497-507.

[72] Tjelle TE, Salte R, Mathiesen I, Kjeken R. A novel electroporation device for gene delivery in large animals and humans. Vaccine 2006; 24: 4667-70.

[73] Lefesvre P, Attema J, van Bekkum D. A comparison of efficacy and toxicity between electroporation and adenoviral gene transfer. BMC Mol Biol 2002; 3: 12.

[74] Hartikka J, Sukhu L, Buchner C, et al. Electroporation-facilitated delivery of plasmid DNA in skeletal muscle: plasmid dependence of muscle damage and effect of poloxamer 188. Mol Ther 2001; 4(5): 407-15.

[75] Molnar MJ, Gilbert R, Lu Y, et al. Factors influencing the efficacy, longevity, and safety of electroporation-assisted plasmid-based gene transfer into mouse muscles. Mol Ther 2004; 10(3): 447-55.

[76] Schertzer JD, Plant DR, Lynch GS. Optimizing plasmid-based gene transfer for investigating skeletal muscle structure and function. Mol Ther 2006; 13(4): 795-803.

[77] Wang Z, Troilo PJ, Wang X, et al. Detection of integration of plasmid DNA into host genomic DNA following intramuscular injection and electroporation. Gene Ther 2004; 11(8): 711-21.

[78] Luckay A, Sidhu MK, Kjeken R, et al. Effect of plasmid DNA vaccine design and in vivo electroporation on the resulting vaccinespecific immune responses in rhesus macaques. J Virol 2007; 81(10): 5257-69.

[79] Gronevik E, Tollefsen S, Sikkeland LI, Haug T, Tjelle TE, Mathiesen I. DNA transfection of mononuclear cells in muscle tissue. J Gene Med 2003; 5(10): 909-17

[80] Luxembourg A, Hannaman D, Nolan E, et al. Potentiation of an anthrax DNA vaccine with electroporation. Vaccine 2008; 26(40): 5216-22.

[81] Uno-Furuta S, Tamaki S, Takebe $\mathrm{Y}$, et al. Induction of virusspecific cytotoxic $\mathrm{T}$ lymphocytes by in vivo electric administration of peptides. Vaccine 2001; 19: 2190-96

[82] Dayball K, Millar J, Miller M, Wan YH, Bramson J. Electroporation enables plasmid vaccines to elicit $\mathrm{CD} 8+\mathrm{T}$ cell responses in the absence of CD4+ T cells. J Immunol 2003; 171: 3379-84

[83] Ahlén $\mathrm{G}$, Söderholm J, Tjelle $\mathrm{T}$, et al. In vivo electroporation enhances the immunogenicity of hepatitis $\mathrm{C}$ virus nonstructural 3/4A DNA by increased local DNA uptake, protein expression, inflammation, and infiltration of CD3+ T cells. J Immunol 2007; 179(7): 4741-53.

[84] Peng B, Zhao Y, Xu L, Xu Y. Electric pulses applied prior to intramuscular DNA vaccination greatly improve the vaccine immunogenicity. Vaccine 2007; 25(11): 2064-73.
[85] Scheerlinck JP, Karlis J, Tjelle TE, Presidente PJ, Mathiesen I, Newton SE. In vivo electroporation improves immune responses to DNA vaccination in sheep. Vaccine 2004; 22(13-14): 1820-5.

[86] Davis HL, Michel ML, Whalen RG. Use of plasmid DNA for direct gene transfer and immunization. Ann N Y Acad Sci 1995; 772: 219.

[87] Long YC, Jaichandran S, Ho LP, Tien SL, Tan SY, Kon OL. FVIII gene delivery by muscle electroporation corrects murine hemophilia A. J Gene Med 2005; 7(4): 494-505.

[88] Nishijima T, Tokura Y, Imokawa G, Seo N, Furukawa F, Takigawa M. Altered permeability and disordered cutaneous immunoregulatory function in mice with acute barrier disruption. J Invest Dermatol 1997; 109: 175-82.

[89] Chiarella P, Massi E, De Robertis M, Fazio VM, Signori E. Strategies for effective naked-DNA vaccination against infectious diseases. Recent Pat Antiinfect Drug Discov 2008; 3(2): 93-101.

[90] Brown BD, Lillicrap D. Dangerous liaisons: the role of "danger" signals in the immune response to gene therapy. Blood 2002; 100(4): 1133-40.

[91] Grønevik E, Mathiesen I, Lømo T. Early events of electroporationmediated intramuscular DNA vaccination potentiate Th1-directed immune responses. J Gene Med 2005; 7(9): 1246-54.

[92] Titomirov AV, Sukharev S, Kistanova E. In vivo electroporation and stable transformation of skin cells of newborn mice by plasmid DNA. Biochim Biophys Acta 1991; 1088: 131-34.

[93] Zhang L, Li L, Hoffmann GA, Hoffman RM. Depth-targeted efficient gene delivery and expression in the skin by pulsed electric fields: An approach to gene therapy of skin aging and other diseases. Biochem Biophys Res Commun 1996; 220: 633-36.

[94] Ni J, Nolte B, Arnold A, Fournier P, Schirrmacher V. Targeting anti-tumor DNA vaccines to dendritic cells via a short CD11c promoter sequence. Vaccine 2009; 27(40): 5480-7.

[95] Akbari O, Panjwani N, Garcia S, Tascon R, Lowrie D, Stockinger B. DNA vaccination: transfection and activation of dendritic cells as key events for immunity. J Exp Med 1999; 189(1): 169-78.

[96] Perrin P, Jacob Y, Aguilar-Sétien A, et al. Immunization of dogs with a DNA vaccine induces protection against rabies virus. Vaccine 1999; 18(5-6): 479-86.

[97] Aihara H, Miyazaki J. Gene transfer into muscle by electroporation in vivo. Nat. Biotechnol 1998; 16: 867-70.

[98] Mir LM, Bureau MF, Gehl J, et al. High-efficiency gene transfer into skeletal muscle mediated by electric pulses. Proc Natl Acad Sci USA 1999; 96: 4262-67.

[99] Mathiesen I. Electropermeabilization of skeletal muscle enhances gene transfer in vivo. Gene Ther 1999; 6: 508-14.

[100] Rubartelli A, Poggi A, Zocchi MR. The selective engulfment of apoptotic bodies by dendritic cells is mediated by the alpha(v)beta3 integrin and requires intracellular and extracellular calcium. Eur J Immunol 1997; 27(8): 1893-900

[101] Albert ML, Pearce SF, Francisco LM, et al. Immature dendritic cells phagocytose apoptotic cells via alphavbeta5 and CD36, and cross-present antigens to cytotoxic T lymphocytes. J Exp Med 1998; 188(7): 1359-68.

[102] Steinman RM, Pope M. Exploiting dendritic cells to improve vaccine efficacy. J Clin Invest 2002; 109(12): 1519-26.

[103] Dupuis M, Denis-Mize K, Woo C, et al. Distribution of DNA vaccines determines their immunogenicity after intramuscular injection in mice. J Immunol 2000; 165: 2850-58

[104] Roos AK, Moreno S, Leder C, Pavlenko M, King A, Pisa P. Enhancement of cellular immune response to a prostate cancer DNA vaccine by intradermal electroporation. Mol Ther 2006; 13(2): 3207.

[105] Smorlesi A, Papalini F, Amici A, et al. Evaluation of different plasmid DNA delivery systems for immunization against HER2/neu in a transgenic murine model of mammary carcinoma. Vaccine 2006; 24(11): 1766-75.

[106] Gronevik E, Mathiesen I, Lomo T. Early events of electroporationmediated intramuscular DNA vaccination potentiate Th1-directed immune responses. J Gene Med 2005; 7(9): 1246-54.

[107] Teicher BA. Transforming growth factor-beta and the immune response to malignant disease. Clin Cancer Res 2007; 13(21) 6247-51.

[108] Kadowaki S, Chen Z, Asanuma H, Aizawa C, Kurata T, Tamura S. Protection against influenza virus infection in mice immunized by administration of hemagglutinin-expressing DNAs with electroporation. Vaccine 2000; 18(25): 2779-88. 
[109] Otten GR, Schaefer M, Doe B, et al. Enhanced potency of plasmid DNA microparticle human immunodeficiency virus vaccines in rhesus macaques by using a priming-boosting regimen with recombinant proteins. J Virol 2005; 79(13): 8189-200.

[110] Tsang C, Babiuk S, van Drunen Littel-van den Hurk S, Babiuk LA, Griebel P. A single DNA immunization in combination with elec- troporation prolongs the primary immune response and maintains immune memory for six months. Vaccine 2007; 25(30): 5485-94.

[111] Bodles-Brakhop AM, Heller R, Draghia-Akli R. Electroporation for the delivery of DNA-based vaccines and immunotherapeutics: current clinical developments. Mol Ther 2009; 17(4): 585-92.

[112] Li S. Delivery of DNA into tumors. Methods Mol Biol 2008; 423 : 311-8.

Received: July 13, 2009

(C) Ni et al.; Licensee Bentham Open.

This is an open access article licensed under the terms of the Creative Commons Attribution Non-Commercial License (http://creativecommons.org/licenses/by-nc/3.0/) which permits unrestricted, non-commercial use, distribution and reproduction in any medium, provided the work is properly cited. 